\title{
PREDICTORS OF SUPERIOR PERFORMANCE IN COACHES - THE ROLE OF A-TRAIT
}

\author{
Radu PREDOIU ${ }^{1}$, Alexandra PREDOIU ${ }^{1 *}$, Ryszard MAKAROWSKI ${ }^{2}$, \\ Andrzej PIOTROWSKI ${ }^{3}$, Raluca PELIN ${ }^{4}$, Georgeta MITRACHE ${ }^{1}$ \\ ${ }^{1}$ National University of Physical Education and Sport, Faculty of Physical Education and Sport, Bucharest, \\ Romania \\ ${ }^{2}$ Elblag University of Humanities and Economics, Faculty of Health Sciences, Elblag, Poland \\ ${ }^{3}$ University of Gdańsk, Institute of Psychology, Gdańsk, Poland \\ ${ }^{4}$ Politehnica University, Faculty of Medical Engineering, Bucharest, Romania \\ *Corresponding author: alexandra.predoiu@ yahoo.com
}

https://doi.org/10.35189/dpeskj.2021.60.3.4

\begin{abstract}
Anxiety represents a multifaceted response that can hinder or help performance. Anxiety experienced at high intensity and in the long term is a noxious phenomenon. However, moderate anxiety can lead to improved performance, stimulating on-task effort. The aims of our study are to determine the pattern of anxious reactions in coaches with superior results in competition and to identify which facet of anxiety is a better predictor of sports performance. A total of 57 coaches (19 women and 38 men) participated in the research. We assessed four facets of trait anxiety using the Endler Multidimensional Anxiety Scales. The results highlight significantly lower scores in successful coaches compared to novice coaches for anxiety in new situations and in separation conditions. When talking about anxiety in physically dangerous and sociallyevaluative circumstances, no significant differences were found between the two groups of coaches (successful and beginner ones). After performing two separate binomial logistic regressions, we can argue that the scores for anxiety in separation conditions are a better predictor of sports performance than anxiety in new situations, the model explaining $30 \%$ of the variance in international or national performance and correctly classifying $75.4 \%$ of cases. The conclusions of our study represent valuable resources for sports psychologists, future (and current) coaches and researchers who are eager to better understand the impact of A-trait on sports performance, in the case of coaches.
\end{abstract}

Keywords: coach, individual sports, trait anxiety, sports performance.

\section{Introduction}

A-trait (trait anxiety) refers to an unpleasant emotion that is characterised by persistent dread (Cashmore, 2002) felt in the absence of true circumstances (this paper investigates trait anxiety and not state anxiety, which represents a transitory emotional condition).

The coaching profession is characterised by the profound uniqueness of its nature. A coach is simultaneously a teacher, a father/mother figure, sometimes even playing the role of a psychologist, but also other roles thought to be necessary at some point.

We mention the following sources of anxiety and stress for coaches in their activity, which are expressed as a percentage (Yow et al., 2011):

- Athletes - we refer to the fear of coaches regarding the performance of athletes on the day of the match, as well as the fear of injury (anxiety of physical danger); it seems that most of the concerns regarding possible injuries occur in the case of football coaches (83\% of male coaches and $90 \%$ of female coaches).

- Performance/Results (we refer to the coach's performance) - this is about the coach's 
fear of not properly preparing athletes for what they have to achieve in a competition and anxiety about possible defeat in important matches or losing matches due to factors that are related to chance or are outside of the coach's control $(67 \%$ of male coaches and $90 \%$ of female coaches feel anxious because of the mentioned sources).

- External influences - these are the worries of specialists (58\% of male coaches and $50 \%$ of female coaches) related to the reactions of fans or unjustified criticism, including from the media (there is anxiety about social evaluation and new, unusual situations).

- Time - insufficient time with the family (separation anxiety occurs), long trips that require a lot of time, insufficient time for the needs of players, worries of coaches due to the need to meet deadlines (33\% of male coaches and $50 \%$ of female coaches).

- Associations - unpleasant interpersonal relationships with members of the multidisciplinary team, difficulties in communicating with them (it may be self-disclosure anxiety), maintaining a stable staff ( $38 \%$ of male coaches and $20 \%$ of female coaches feel anxious and stressed about this).

In sport, an emotion is a cognitively appraised (conscious or unconscious) response to competition (Frederickson, 2001; Predoiu, 2016), which triggers multiple responses (physiological changes and cognitive processing). Therefore, anxiety manifests at somatic and cognitive levels (sweaty hands, irregular breathing, rapid heartbeat or/and fear of failure, lack of self-confidence, difficulty concentrating, etc.). We underline some challenges considering anxiety in sport. Emotional states that are felt as unpleasant may not be linked to a negative impact on performance (Woodman \& Hardy, 2001), as positive/pleasant emotional states may not be linked to appropriate responses in competition. Hanin (1997) talks about four categories of emotions: pleasant (positive) and functional $(\mathrm{P}+)$, pleasant and dysfunctional ( $\mathrm{P}-)$, unpleasant (negative) and functional $(\mathrm{N}+)$, unpleasant and dysfunctional $(\mathrm{N}-)$. Functional pleasant and unpleasant emotional experiences $(\mathrm{P}+$ and $\mathrm{N}+$ ) accompany increased performance, while dysfunctional pleasant and unpleasant emotional experiences ( $\mathrm{P}$ - and $\mathrm{N}-$ ) are usually associated with low sports performance. But we should not forget that athletes and coaches experience a constellation of emotional states during the competition. It may also be difficult for athletes and coaches to differentiate between feelings associated with a specific stimulus and those that may already be present - taking into account a mood state (Lane \& Terry, 2000).

In sports performance, specialists talk about an optimal anxiety zone (Krane, 1993). But sports performance is idiosyncratic, so this optimal zone is different from one athlete to another (see Pelin et al., 2020, for different mental features of top level athletes). We also mention that anxiety (e.g., at high intensity) could be interpreted in various ways by athletes and coaches. Researchers make reference to facilitative or debilitative anxiety (Hanton et al., 2004). In this context, goal attainment and coping ability represent mediators of anxiety interpretation.

Anxious people assume a higher stimulating risk and act (for example, in competitions) according to the all-or-nothing principle (Makarowski et al., 2016). There is a very close connection between anxiety and stress, the two mental phenomena influencing each other (Predoiu, 2016). When sports stressors lead to anxiety, this anxiety is considered sportsrelated strain (Beehr \& McGrath, 1992). If an athlete perceives a stressor (e.g., a basketball 
player taking a free throw) as a threat and doubts their ability to succeed, the most likely emotion elicited will be anxiety. If we accept that anxiety is an emotion and that cognitive evaluation in sport precedes an emotion (Ochsner \& Gross, 2007), then it becomes very important to be aware of the cognitive precursors to anxiety in controlling it. As Gould et al. (1984) emphasised, suitable interventions could be designed for both athletes and coaches (considering their reactions in competitions) to determine the antecedents of anxiety in competitive circumstances. Researchers could start this process knowing that more important competitions are linked to heightened anxiety responses, which in turn affect sports performance (Dowthwaite \& Armstrong, 1984; Grigore et al., 2015).

Considering the association between anxiety and performance, several theories dominate the literature, but the cusp catastrophe model and the processing efficiency theory are among the most important. According to the first model (Hardy \& Parfitt, 1991; Hardy et al., 1994): a) when cognitive anxiety is high (the person worries too much), the effect of physiological arousal on performance can be negative or positive; b) when physiological arousal is high, a negative association can be found between cognitive anxiety and performance; c) at low levels of cognitive anxiety, shifts in physiological arousal result in continuous and small changes in performance. The processing efficiency theory explains why anxiety sometimes improves performance (Eysenck \& Calvo, 1992). Thus, to avoid negative consequences due to poor performance, anxious athletes (or coaches) may be more motivated and put more effort into a given task. The theory also predicts that cognitive anxiety (worries) negatively influences working memory (which involves data storage and processing), diverting attention concentration from task-relevant cues. There are also authors who have merged the two theories (Hardy et al., 2007). Investigating the competitive anxiety literature, practitioners and researchers focused on the amount of somatic and cognitive symptoms experienced by participants (especially athletes) in competitions and found that high-intensity levels (considering anxiety) were invariably detrimental to success in sport (Mellalieu \& Hanton, 2009).

Over time, the personality of coaches has been studied (anxiety represents a personality trait) but less compared to the personality of professional athletes. We present the following personality traits specific to the successful coach, which leave their mark on the development of athletes and have a facilitating role in sports performance (Predoiu et al., 2020; Mumford et al., 2017; Kavussanu et al., 2008; Ciolcă et al., 2019): low level of neuroticism and high level of agreeableness, openness and conscientiousness; ability to make decisions, ability to delegate, to work independently, to develop others, leadership skills and internal locus of control (successful coaches are aware of the impact of their behaviour on athletes); success and failure are related to their own abilities and not to external factors; goal-oriented, predominantly charismatic, altruistic and motivated, a top coach can better manage the immediate non-fulfilment of needs in order to achieve an important goal; good emotional intelligence (empathy, social skills, self-control, self-awareness, inner motivation); patience, calm and understanding - vital features for the quality of the coach-athlete relationship; planning skills, creative thinking, vision, evaluation of ideas and ability to motivate athletes. Finally, top coaches have the ability to work hard at a fast personal pace, are interested in their own professional development and growth and are able to follow a predetermined plan or programme. From the information provided above, we can deduce that the successful 
coach does not have a high score in the case of anxiety as a trait. However, it has been noticed that there are different facets of anxiety (four are approached in this paper), the level at which each facet manifests itself in top coaches being a topic that is far from over. Furthermore, the predictive ability of different facets of anxiety (we refer to the ability to predict sports performance) is an almost non-existent topic in the literature.

Regarding A-trait in the case of experienced football coaches, we notice a score below average in situations of separation from an important person as well as in situations of physical danger and an average or slightly below average score in new, unusual situations and in socially-evaluative conditions (Palade et al., 2018). The authors explain these findings, considering the mentioned facets of trait anxiety, as follows:

- through the longer participation of specialists in workouts, competitions, training camps and internships carried out in the home country or abroad, they have become over time less anxious about the separation from an important person;

- the acquired experience has also left its mark on the anxiety felt by experts in new, unfamiliar situations, producing desensitisation and thus the proper management (average level of anxiety) of new situations involving different stimuli with anxiogenic potential;

- the higher score obtained by experienced football coaches (compared to future football coaches) for physical danger anxiety is explained by the fact that specialists in the field are more aware of the importance of avoiding football injuries. This slightly higher level of anxiety (essentially, a slightly below average and below average level according to the standard/norms) in physically dangerous situations can lead to better training from a technical, tactical and physical point of view, experts anticipating potentially harmful problems during the competition;

- the higher score obtained by football coaches with seniority and performance in the field (compared to future football coaches) for social evaluation anxiety is explained by their participation in press conferences and discussions with parents or other officials, or as a result of media pressure. All these career moments when specialists can be observed, evaluated or judged influence their way of relating to the environment, a slightly higher level of anxiety (essentially, an average or slightly below average level according to the standard/norms) helping them to anticipate and react appropriately to external demands.

The current research complements the information provided by the above study from two points of view. On the one hand, successful coaches in individual sports were investigated, and on the other hand, the present study aims to predict the probability for coaches to obtain superior performance in competitions, starting from their scores for different facets of anxiety (a less approached topic in the literature).

Regarding athletes' anxiety, the path is well trodden. Various researchers have predicted sports performance using cognitive or/and somatic anxiety (Taylor, 1987; Jones et al., 2004; Mabweazara et al., 2017). Instead, considering coaches (or spectators, sports officials), understanding their level of anxiety and its impact on sports performance might lead to significant advances. We argue that the current literature pays less attention to the ways of working with coaches (Sheehy et al., 2019) and to the way of developing desirable behaviors in coaches (Pelin et al., 2018). 
The goals of our research are to identify what is specific for coaches with superior results in competition, taking into account A-trait, and to determine which facet of anxiety is a better predictor of sports performance.

Starting from the investigations of Predoiu et al. (2020), Kavussanu et al. (2008), Palade et al. (2018) and Ciolcă et al. (2019), the following hypothesis arises:

$H 1$ : Studying trait anxiety reveals significant differences between successful coaches (with international or national performance) and novice coaches.

McGarry et al. (2021) highlight that, if there is limited literature in a research area (in our case, the predictive ability of A-trait factors on sports performance in coaches), then the hypotheses are not formed. Therefore, we formulated the following research question: Which facet of anxiety is a better predictor of sports performance in individual sports coaches?

\section{Methodology}

\section{Participants}

Fifty-seven coaches participated in the research. The distribution of coaches $(C)$ according to sports performance, gender (raw scores and percentages) and practised sport is as follows:

- $\mathrm{C}_{1}$ : coaches with international results (at Olympic, World or European level) - 1 woman (11.1\%) and 8 men (88.9\%); practised sports: skiing, athletics, martial arts, tennis, canoeing and kayaking, badminton and artistic gymnastics;

- $\mathrm{C}_{2}$ : coaches with national results (training athletes who are members of national teams, national champions or vice-champions) - 6 women (33.3\%) and 12 men (66.6\%); practised sports: skiing, athletics, martial arts, tennis, swimming, aerobic and artistic gymnastics;

- $\mathrm{C}_{3}$ : novice coaches (who have recently obtained their diplomas as sports coaches, some in 2018, others in 2019) - 12 women (40\%) and 18 men (60\%); practised sports: the same as $\mathrm{C}_{2}$ coaches (at the time of testing, they had achieved local results with their athletes).

The age of the 57 coaches was between 23 and 26 years (for novice coaches, at the beginning of their careers), and between 35 and 66 years (for coaches with international and/ or national performance).

\section{Instruments}

In order to measure trait anxiety, the Endler Multidimensional Anxiety Scales (EMAS) were used, more exactly, three EMAS-T Scales (measuring anxiety in new or ambiguous, socially-evaluative and physically dangerous situations) and one SAS-T Scale (measuring anxiety in separation conditions).

Each scale consists of 15 items (the same 15 items in each scale), participants being asked to imagine themselves in the situation described in the standard tutorial. Therefore:

- anxiety in new or ambiguous circumstances (standard tutorial) - "We are interested in your reactions to new, unfamiliar situations and when you are not sure what to expect";

- anxiety in socially-evaluative situations - "We are interested in your reactions to the situations in which you are evaluated, observed, judged by other people"; 
- anxiety in physically dangerous conditions - "We are interested in your reactions to the situations that involve dealing with physically dangerous or potentially harmful things, objects or events";

- anxiety in separation situations - "We are interested in your reactions to the situations in which you are separated from an important person in your life for at least one week".

Coaches responded on a 5-point Likert scale, where 1 denotes "Not at all", and 5 - "Very much". Examples of items: "I feel comfortable", "I feel worried", "I am agitated", "I trust myself", etc. A social desirability measure was also used to minimise the likelihood of inappropriate responses from coaches, namely the Desirability Scale of the ZuckermanKuhlman Personality Questionnaire (no coach was removed from the study following the responses to this scale).

Anxiety scales are calibrated for the Romanian population by the Cognitrom Company, EMAS being part of the Cognitrom Assessment System (a computerised platform developed by Cognitrom). The interpretation of the scores ( $t$ values) is as follows: under $40=$ low values; $40-45=$ slightly below average values; $45-55=$ average values; $55-60=$ slightly above average values; over $60=$ high values.

\section{Procedure}

Participants filled out the EMAS-T and SAS-T Scales between April and June 2020. The study was conducted via the Internet, coaches receiving the four anxiety scales on their personal email addresses. The research took place in Romania. Ethical principles were ensured, data were treated confidentially, and the informed written consent of the participants was obtained.

\section{Quasi-experimental design}

In the first phase, the results obtained by coaches for the four facets of trait anxiety play the role of dependent variables, while their membership in one of the two groups, "successful" or "beginner" coaches, plays the role of the independent variable. In the second part of our paper, sports performance represents the dependent variable, and the scores recorded by coaches for A-trait represent the independent variable.

\section{Results}

First, we were interested in highlighting the facets of trait anxiety specific to coaches with superior results in competition. Due to the reduced number of specialists with international performance $(n=9)$, we merged the two groups of coaches (with national and international results).

The t-Test for Independent Samples was used to identify whether there were significant differences between successful coaches and novices, considering the four facets of trait anxiety (Table 1). We underline that Levene's test results were insignificant $-\mathrm{p}>0.05$ (the homogeneity of variances being assumed) and skewness values were less than 1 (the dependent variables being normally distributed). 
Table 1. Descriptive statistics - Specialists (having international and/or national results) and novice coaches

\begin{tabular}{lcccc}
\hline \multirow{2}{*}{ Measure } & \multicolumn{2}{c}{$\begin{array}{c}\text { Coaches having international and/or } \\
\text { national results }\end{array}$} & \multicolumn{2}{c}{$\begin{array}{c}\text { Beginner coaches - having local/ } \\
\text { regional results }\end{array}$} \\
\cline { 2 - 5 } & $M$ & $S D$ & $M$ & $S D$ \\
\hline A-N/A & 48.30 & 6.94 & 53.27 & 6.01 \\
AS-E & 47.00 & 8.32 & 50.13 & 6.81 \\
AP-D & 38.19 & 4.55 & 40.50 & 5.88 \\
A-SEP & 34.00 & 6.88 & 40.47 & 5.27 \\
\hline
\end{tabular}

Note. A-N/A: anxiety in new or ambiguous conditions; AS-E: anxiety in socially-evaluative situations;

AP-D: anxiety in physically dangerous situations; A-SEP: anxiety in separation circumstances.

We emphasise that the mean value for anxiety in new circumstances is significantly lower $[\mathrm{t}(55)=-2.896, \mathrm{p}=0.005]$ for successful coaches (who obtained a medium score) compared to novice coaches (who also recorded a moderate score according to the norms, but significantly higher than top coaches). The effect size index (Hedge's $g=0.76$ ) reflects a moderate to strong difference (Predoiu, 2020) between the results (for anxiety in ambiguous/ new situations) of successful coaches and beginners. The confidence interval is comprised between -8.409 (lower limit) and -1.531 (upper limit). We also highlight a significant difference between the two groups of coaches, considering anxiety in separation conditions $[\mathrm{t}(55)=-4.003, \mathrm{p}=0.000]$. Successful coaches obtained a low score, while novices recorded a slightly below average value. The effect size index (Hedge's $g=1.06$ ) translates into a strong to very strong difference between the results. The confidence interval of the difference is comprised between -9.704 (lower limit) and -3.229 (upper limit).

When talking about anxiety in physically dangerous and socially-evaluative circumstances, no significant differences were highlighted.

In the second phase, knowing that anxiety in new conditions and in separation situations is specific to successful coaches (the values are generally at a moderate or slightly below average level for A-N/A and at a low level for A-SEP), we checked to what extent the two facets of A-trait predicted sports performance. We assumed to predict the likelihood of international or national results in coaches based on their scores for the two facets of anxiety.

Two binomial logistic regressions were achieved (for each facet of A-trait). The two models are significant (Omnibus test $-\mathrm{p}<.05$ ). Regarding the Hosmer \& Lemeshow Goodness of Fit Test, the results are not significant for A-N/A and A-SEP ( $p=0.790$ and $p=$ 0.108 , respectively), indicating that the models are not a poor fit. The logistic regression models were significant: A-N/A - $\chi 2(1)=8.07, \mathrm{p}<.01$; A-SEP $-\chi 2(1)=14.67, \mathrm{p}<.001$. In the case of coaches, we can state that A-SEP is a better predictor of sports performance than A-N/A. The models explained $17 \%$ (A-N/A) and 30\% (A-SEP) (Nagelkerke $\mathrm{R}^{2}$ ) of the variance in international or national performance and correctly classified $70.2 \%$ (A-N/A) and $75.4 \%$ (A-SEP) of cases. Sensitivity was $59.3 \%$ and specificity was $80 \%$ for anxiety in new/ ambiguous situations, while sensitivity was $74.1 \%$ and specificity was $76.7 \%$ for anxiety in separation conditions. The Wald test value is $6.61, B=0.12(\mathrm{SE}=0.05)$ for A-N/A, while Wald $=10.23, B=0.18(\mathrm{SE}=0.06)$ for A-SEP. We argue that the contribution of the two variables to predicting sports performance in coaches is relatively important (the odds ratio values are below 0.850). 


\section{Conclusion}

The purposes of our research were to highlight what was specific to coaches with superior results in competitions, considering trait anxiety, and to identify which facet of A-trait was a better predictor of sports performance.

First, we emphasised that anxiety in new situations and in separation circumstances was specific to successful coaches. Coaches' scores for the two facets of anxiety generally indicate a moderate level/slightly below average level (A-N/A) and a low level (A-SEP). We can explain these results through the fact that successful coaches, having a greater experience in terms of travel, competitions and training camps with athletes, are more accustomed to the temporary separation from important/significant persons. Also, dealing over time with various situations in training and competition (we can think of parents, athletes, officials, supporters, media, etc.) has led to the manifestation of a moderate/slightly below average level of anxiety in new conditions (by comparison with novice coaches, who generally recorded moderate/slightly above average scores for A-N/A). Even if no significant differences were found between the two groups of coaches when talking about AP-D and AS$\mathrm{E}$, interesting aspects could be highlighted. Thus, coaches having international or national results recorded an average score for anxiety in socially-evaluative situations and a low score for anxiety in dangerous conditions, while beginners (young coaches with local level performance) obtained a slightly higher score than successful coaches for AS-E and a slightly below average result for AP-D.

The next step consisted in checking to what extent A-N/A and A-SEP predicted sports performance. Starting from our research question and after analysing the most important data of the main logistic regression procedures, we can state that the scores for anxiety in separation situations represent a better predictor of sports performance than anxiety in new conditions. We can explain the importance of this facet of A-trait in sports performance if we refer to the relationship (of mutual influence) between anxiety and stress. A coach who is less anxious (and stressed) due to separation from an important person can better focus on tactics, pay more attention to detail, better comply with the pre-competition plans/strategies and, why not, facilitate an ideal mental state in athletes. Researchers highlight the importance of developing the ability to control stress (and anxiety) as soon as one's career begins, for better health management (Piotrowski, 2018).

In practice, we recommend to influence coaches' anxiety (Hanton \& Jones, 1999; Grigore et al., 2015; Jones, 2003) through multimodal interventions (comprising a number of strategies). Specialists could use these strategies to minimise the intensity of symptoms or encourage coaches to evaluate their symptoms more positively (Uphill \& Jones, 2007). For example, coaches could be encouraged to exercise more control over how they behave and think in response to a specific situation, being aware of the coach-athlete dyad (the athlete and the coach influence each other in competition).

The following limitations are raised: the different sports practised by coaches and the possible effects of the COVID-19 pandemic on their anxiety (knowing that COVID-19 might cause symptoms consistent with generalised anxiety disorder - Schinke et al., 2020; Pfefferbaum \& North, 2020). Future investigations are needed to examine other facets of A- 
trait, which include a greater number of coaches with international results, specialists in team sports (not only individual sports as in our study) and larger samples for each practised sport.

\section{Authors' Contributions}

All authors have equally contributed to this study.

\section{References}

Beehr, T. A., \& McGrath, J. E. (1992). Social support, occupational stress and anxiety. Anxiety, Stress \& Coping, 5(1), 7-19. https://doi.org/10.1080/10615809208250484

Cashmore, E. (2002). Sport psychology. Routledge.

Ciolcă, S., Palade, T., Grigore, G., \& Predoiu, R. (2019). The model regarding personality of the future coach with football specialisation. European Proceedings of Social and Behavioural Sciences, LV, 171-177. https://dx.doi.org/10.15405/epsbs.2019.02.21

Dowthwaite, P. K., \& Armstrong, M. R. (1984). An investigation into the anxiety levels of soccer players. International Journal of Sport Psychology, 15(2), 149-159.

Eysenck, M. W., \& Calvo, M. G. (1992). Anxiety and performance: The processing efficiency theory. Cognition and Emotion, 6(6), 409-434. https://doi.org/10.1080/02699939208409696

Frederickson, B. L. (2001). The role of positive emotions in positive psychology. American Psychologist, 56(3), 218-226. PMID: 11315248

Gould, D., Petchlikoff, L., \& Weinberg, R. S. (1984). Antecedents of temporal changes in, and relationships between CSAI-2 subcomponents. Journal of Sport Psychology, 6(3), 289-304. https://doi.org/10.1123/jsp.6.3.289

Grigore, V., Mitrache, G., Predoiu, R., Păunescu, M., \& Radu, A. (2015). Trait anxiety and coping strategies in aerobic gymnastics and handball. Medimond International Proceedings - 4th International Congress of Physical Education, Sport and Kinetotherapy (ICSPEK 2014), 193-198. WOS: 000360246100032

Hanin, Y. L. (1997). Emotions and athletic performance: Individual zones of optimal functioning model. In D. Smith \& M. Bar-Eli (Eds.), Essential readings in sport and exercise psychology (pp. 55-73). Human Kinetics.

Hanton, S., \& Jones, G. (1999). The effects of a multimodal intervention programme on performers: II. Training the butterflies to fly in formation. The Sport Psychologist, 13(1), 22-41. https://doi.org/10.1123/tsp.13.1.22

Hanton, S., Thomas, O., \& Maynard, I. W. (2004). Competitive anxiety response in the week leading up to competition: The role of intensity, direction and frequency dimensions. Psychology of Sport and Exercise, 5(2), 169-181. https://doi.org/10.1016/S1469-0292(02)00042-0

Hardy, L., \& Parfitt, G. (1991). A catastrophe model of anxiety and performance. British Journal of Psychology, 82(Pt 2), 163-178. https://doi.org/10.1111/j.2044-8295.1991.tb02391.x

Hardy, L., Beattie, S., \& Woodman, T. (2007). Anxiety-induced performance catastrophes: Investigating effort required as an asymmetry factor. British Journal of Psychology, 98(Pt 1), 15-31. https://doi.org/10.1348/000712606x103428

Hardy, L., Parfitt, G., \& Pates, J. (1994). Performance catastrophes in sport: A test of the hysteresis hypothesis. Journal of Sports Sciences, 12(4), 327-334.

https://doi.org/10.1080/02640419408732178 
Jones, K. A., Smith, N. C., \& Holmes, P. S. (2004). Anxiety symptom interpretation and performance predictions in high-anxious, low-anxious and repressor sport performers. Anxiety, Stress \& Coping: An International Journal, 17(2), 187-199. https://doi.org/10.1080/10615800410001710870

Jones, M. V. (2003). Controlling emotions in sport. The Sport Psychologist, 17(4), 471-486. https://doi.org/10.1123/tsp.17.4.471

Kavussanu, M., Boardley, I. D., Jutkiewicz, N., Vincent, S., \& Ring, C. (2008). Coaching efficacy and coaching effectiveness: Examining their predictors and comparing coaches' and athletes' reports. Sport Psychologist, 22(4), 383-404. https://doi.org/10.1123/TSP.22.4.383

Krane, V. (1993). A practical application of the anxiety-athletic performance relationship: The zone of optimal functioning hypothesis. The Sport Psychologist, 7(2), 113-126. https://doi.org/10.1123/tsp.7.2.113

Lane, A. M., \& Terry, P. C. (2000). The nature of mood: Development of a conceptual model with a focus on depression. Journal of Applied Sport Psychology, 12(1), 16-33. https://doi.org/10.1080/10413200008404211

Mabweazara, S. Z., Leach, L., \& Andrews, B. S. (2017). Predicting swimming performance using state anxiety. South African Journal of Psychiatry 47(1), 1-11. https://doi.org/10.1177\%2F0081246316645060

Makarowski, R., Makarowski, P., \& Kamiński, Z. (2016). Adrenaline instead of amphetamine - Replacing psychoactive substances with parachute jumps. The Journal of General Psychology, 143(4), 281-297. http://dx.doi.org/10.1080/00221309.2016.1214101

McGarry, K. A., West, M., \& Hogan, K. F. (2021). Perspective-taking and social competence in adults. Advances in Cognitive Psychology, 17(2), 129-135. https://doi.org/10.5709/acp-0323-5

Mellalieu, S., \& Hanton, S. D. (Eds.) (2009). Advances in applied sport psychology: A review. Routledge.

Mumford, M. D., Todd, E. M., Higgs, C., \& McIntosh, T. (2017). Cognitive skills and leadership performance: The nine critical skills. The Leadership Quarterly, 28(1), 24-39. https://doi.org/10.1016/j.leaqua.2016.10.012

Ochsner, K. N., \& Gross, J. J. (2007). The neural architecture of emotion regulation. In J. J. Gross (Ed.), Handbook of emotion regulation (pp. 87-109). Guilford Press.

Palade, T., Grigore, G., Ciolcă, S., \& Predoiu, R. (2018). A matrix of anxiety as a trait of the football specialist. European Proceedings of Social and Behavioural Sciences, XXXVI, 5360. http://dx.doi.org/10.15405/epsbs.2018.03.7

Pelin, F., Predoiu, R., Mitrache, G., \& Predoiu, A. (2020). Mental features of top level athletes. Discobolul - Physical Education, Sport and Kinetotherapy Journal, 59(1), 5-14. https://doi.org/10.35189/dpeskj.2020.59.1.1

Pelin, F., Predoiu, R., Mitrache, G., Predoiu, A., \& Grigore, V. (2018). Generation of efficient behaviours in the case of performance athletes. Discobolul - Physical Education, Sport and Kinetotherapy Journal, 53, 31-38.

Pfefferbaum, B., \& North, C. S. (2020). Mental health and the COVID-19 pandemic. The New England Journal of Medicine, 383(6), 510-512. https://www.nejm.org/doi/10.1056/NEJMp2008017

Piotrowski, A. (2018). Self-evaluation of personal physical health, accidents while performing duty and preventive treatment of stress in Prison Service [Article in Polish]. Medycyna Pracy, 69(4), 425-438. https://doi.org/10.13075/mp.5893.00535

Predoiu, A. (2020). Metodologia cercetării științifice. Aplicații practice și elemente de statistică neparametrică [Scientific research methodology. Practical applications and elements of nonparametric statistics]. Discobolul. 
Predoiu, R. (2016). Psihologia sportului. Maximizarea performanței sportive [Sport psychology. Maximisation of sports performance]. Polirom.

Predoiu, R., Makarowski, R., Görner, K., Bota, A., Predoiu, A., Mitrache, G, \& Grigore, V. (2020). Key personality traits of martial arts and world's top coaches - Impact on future martial arts specialists. Archives of Budo, 16, 129-142. WOS: 000579413000001

Schinke, R., Papaioannou, A., Maher, Ch., Parham, V. D., Larsen, C. H., Gordin, R., \& Cotterill, S. (2020). Sport psychology services to professional athletes: Working through COVID-19. International Journal of Sport and Exercise Psychology, 18(4), 409-413. https://doi.org/10.1080/1612197X.2020.1766182

Sheehy, T. L., Dieffenbach, K., \& Reed, P. (2019). An exploration of coaching research in Journal of Applied Sport Psychology from 1989 to 2017. Journal of Applied Sport Psychology, 31(3), 352-365. https://doi.org/10.1080/10413200.2018.1494642

Taylor, J. (1987). Predicting athletic performance with self-confidence and somatic and cognitive anxiety as a function of motor and physiological requirements in six sports. Journal of Personality, 55(1), 139-153. https://doi.org/10.1111/j.1467-6494.1987.tb00432.x

Uphill, M. A., \& Jones, M. V. (2007). "When running is something you dread": A cognitivebehavioural intervention with a club runner. In A. M. Lane (Ed.), Mood and human performance: Conceptual, measurement and applied issues (pp. 271-295). Nova Science.

Woodman, T., \& Hardy, L. (2001). Stress and anxiety. In R. N. Singer, H. A. Hausenblas, \& C. M. Janelle (Eds.), Handbook of sport psychology (pp. 290-318). Wiley.

Yow, D. A., Humphrey, J. H., \& Bowden, W. W. (2011). Stress factors in the profession of coaching: Assessing their nature, scope and impact. In J. A. Morelli, \& O. D. Velez (Eds.), Coaching and management techniques in athletics (pp. 43-58). Nova Science Publishers, Inc. 